\title{
Load Frequency Control of Interconnected Power Systems Using Hybrid Algorithm Based Particle Swarm and Grey Wolf Optimizers
}

\author{
Mohamed A Sobhy ${ }^{I^{*}}$, Mohamed E Abdelrahman ${ }^{1}$, Hany M Hasanien ${ }^{1}$, \\ Almoataz, Y Abdelaziz', and Ahmed F. Zobaa ${ }^{2}$ \\ ${ }^{1}$ Departement of Electrical Power \& Machines, Faculty of Engineering, Ain Shams University, Cairo, Egypt \\ ${ }^{2}$ Electronic and Electrical Engineering Department, Brunel University London, Uxbridge, United Kingdom \\ *mohamed_sobhy@eng.asu.edu.eg
}

Keywords: Grey Wolf optimization, Particle Swarm optimization, hybrid Optimization, load frequency control.

\begin{abstract}
This study introduces a new hybrid optimization technique into the research field of load frequency control. The new technique is a hybrid technique that combines two metaheuristic-based algorithms: Particle Swarm Optimizer (PSO) and Grey Wolf Optimization (GWO). This new technique facilitates the selection of the best gain values of the controller used in the power system under study. The controller utilized in this study is the classical proportional-integral-derivative (PID) controller. This classical controller is selected in this study to make a reliable comparison with other applied techniques. The study's main goal is to retain the system frequency and tie-line power within permissible limits after applying a load disturbance to one of the system areas. The system under test is built as a three area network with thermal power generation units. The hybrid PSO-GWO (HPSOGWO) algorithm is applied to the system under test. The results obtained are verified by comparing them with other techniques, including the bacterial foraging technique (BFOA) and harmony search technique (HS). The results show that the HPSOGWO algorithm can preserve the frequency and tie-line power within the permissible bounds faster and with better transient specifications than that obtained using the other algorithms under comparison. The three area system is simulated in MATLAB environment for an easier interface.
\end{abstract}

\section{Introduction}

The frequency control problem is considered a main and vital topic in the field of power system control. The major aim of load frequency control is to handle the issue of frequency deviation in addition to power mismatch due to applying step load variations. Aiming to reach this target, the steady-state error of the frequency in addition to the error of tie-line power should be zero [1-4]. The requirements above must be fulfilled during normal and disturbed conditions where a step load is applied to one of the system areas [5-9].

Over the previous decades, the problem of load frequency control earned great attention and huge efforts from the power system control researchers trying to improve the power system performance and enhance the system stability under dynamic loading [10-16]. Consequently, various control strategies were developed to handle the problem of load frequency control, such as fuzzy logic controller [9], fractional-order controller [18], neural network controller [19], robust controllers [20], Ho controller [21], and many other controllers are used. These controllers have shown their capability of giving good transient specifications with dynamic systems. Still, on the other hand, these controllers suffer from various vulnerabilities, including a long time of computation, the requirement for designer experience, and their high cost.

The classical controllers, such as PID controllers, have the major portion of usage in the industry due to their uncomplicated structure, low cost and high stability margin [3]. On the other hand, these controllers suffer from their high sensitivity to any system parameters changes; they are also sensitive to the system non-linearities. These drawbacks complicate selecting the optimal gains of the classical controllers and represent a great obstacle for the designers [22-26].

Therefore, a tremendous number of optimization techniques were developed to select the optimum gain values of the classical controller. Among these techniques, genetic algorithm [26], firefly algorithm [27], whale optimization technique [28], bacterial foraging algorithm [13] and artificial bee colony optimization technique [29] are implemented. 


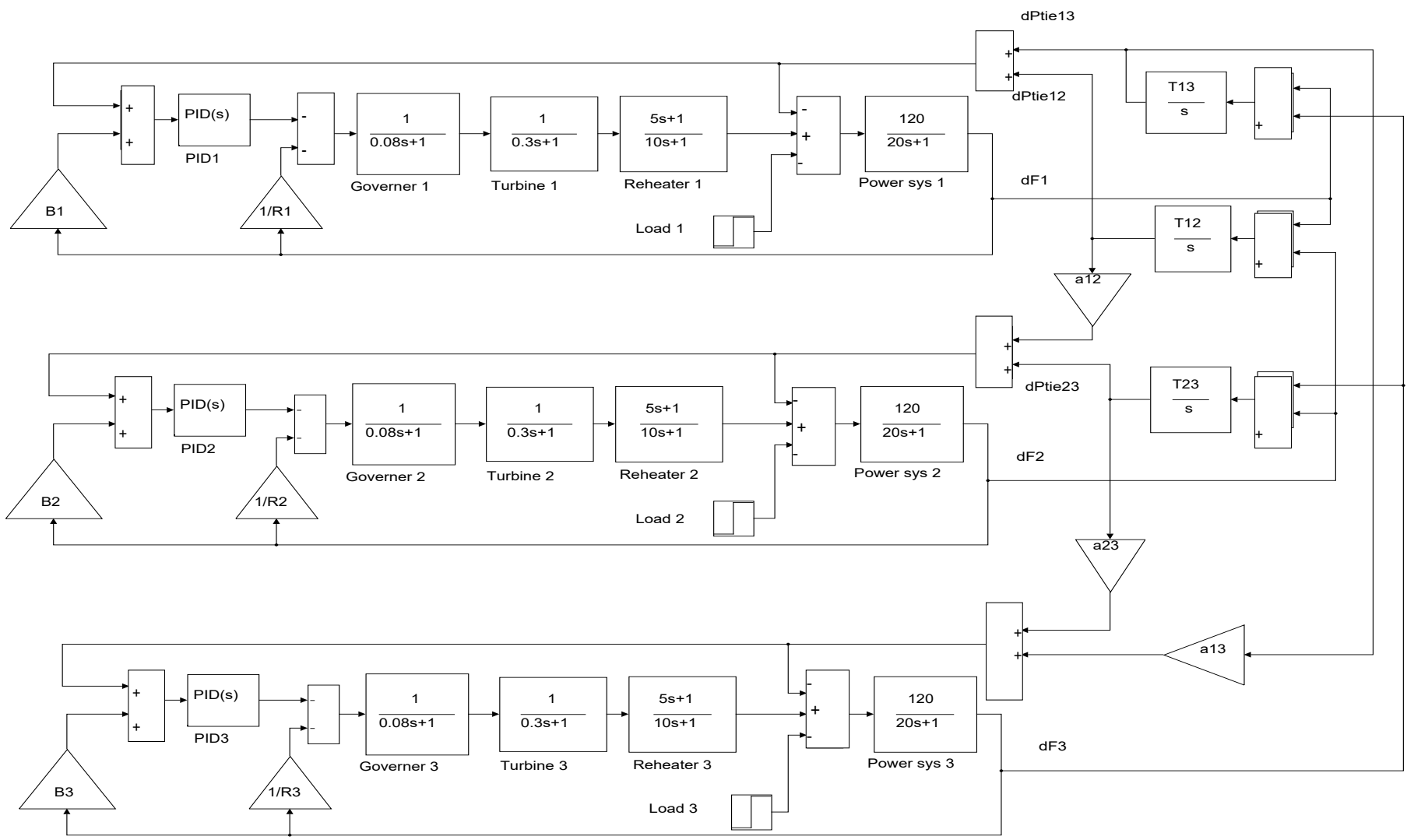

Fig.1. Three area interrconnected power system

The Hybrid Particle Swarm Optimizer- Grey Wolf Optimizer (HPSOGWO) technique is a new hybrid optimization technique [30]. The main goal of this hybridization is to enhance the capability of exploitation in the Particle Swarm algorithm and enhance the capability of exploration of the GWO. Also, this hybridization enhances the convergence capabilities and improves the robustness of the GWO, as described in [30].

This study utilizes the suggested HPSOGWO algorithm to tune the gain coefficients of the controllers used in a threeareas interconnected network. The effectiveness of the HPSOGWO technique is examined where its output is compared with different techniques. The system is simulated using SIMULINK to facilitate the analysis.

The structure of this article is coordinated as follows: The system paradigm and analytical formulation of LFC are discussed in section 2. In section 3, the proposed HPSOGWO algorithm is explained. The simulation outcomes are depicted in section 4. The conclusions are introduced in section 5 .

\section{Network Paradigm and mathematical representation}

The network paradigm comprises three area systems composed of three unequal interconnected areas, as shown in Fig.1. The generating units are thermal units with single reheat turbines. The block model of all system components is introduced in Table 1. The scheduled power rating of the three areas is as follows: area-1 has 2 GW capacity, area- 2 has 4 GW capacity, and area- 3 has 8 GW capacity. The details of system variables are extracted from [3]. The system parameters are depicted in Table 2, where $R$ stands for the governor speed coefficient, $B$ indicates the frequency bias coefficient of a control region. Where $T_{g}$ stands for governor the first-order time factor, $T_{t}$ indicates the first-order time factor of the turbine, $K_{h}$ is the reheater gain, and $T_{h}$ indicates the reheater time constant. $K_{p s}$ represents the gain factor of the area, and $T_{p s}$ stands for its time constant. Also, $T_{12}, T_{13}$ and $T_{23}$ represent the synchronizing constants. $\Delta F$ indicates the frequency variation while $\Delta P_{t i e}$ is the variation of tie-line power [31-38]. The system model is built in MATLAB environment to facilitate the tuning process of the PID controller and select the controller coefficients.

Table 1 Transfer functions of three area system

\begin{tabular}{lc}
\hline Block name & S-domain representation \\
\hline Governor & $1 /\left(s . T_{g}+1\right)$ \\
Turbine & $1 /\left(s . T_{t}+1\right)$ \\
Reheater & $\left(s . K_{r} T_{r}+1\right) /\left(s . T_{r}+1\right)$ \\
Power system & $K_{p s} /\left(s . T_{p s}+1\right)$ \\
\hline
\end{tabular}

The major target of using the HPSOGWO technique is to tune the controller allowing it to give the best dynamic response. The controller used in this article is the classical PID controller. The parallel PID controller has four coefficients which are the proportional control factor $\left(k_{p}\right)$, the integral control factor $\left(k_{i}\right)$, the derivative control factor $\left(k_{d}\right)$ and the filter gain factor $(N)$. The filter's primary function is to damp 
the noise oscillations at large frequencies, where these oscillations are caused by the controller derivative action [4].

The mathematical formulation of the parallel PID controller can be expressed using Laplace transform as follows:

$$
G_{c}=k_{p}+k_{i} \cdot\left(\frac{1}{s}\right)+k_{d} \cdot \frac{N}{1+(N / s)}
$$

The signal fed to the PID block is called area control error (ACE). This signal represents an analytical combination between the frequency deviation and the change in line power [6]. Load frequency control problem is analytically represented as an objective function that has to be minimized. The optimization problem is solved via the method of integral square error (ISE). The HPSOGWO technique minimizes the fitness function for tunning the PID controllers without violating the maximum and minimum limits of the gain values. The optimization problem is mathematically formulated as follows [3] :

$I S E=\int_{0}^{t_{S}}\left\{\left(\sum \Delta F_{i}\right)^{2}+\left(\sum \Delta P_{\text {tie } x y}\right)^{2}\right\} \cdot d t$

Where $\Delta F_{i}$ indicates the frequency error in area- $x$, $\Delta P_{\text {tie } x y}$ indicates the error in the power of the line linking region $x$ and region $y$. In contrast, $t_{\mathrm{s}}$ indicates the time taken for simulating the system paradigm.

Table 2 Three area system variables

\begin{tabular}{ll}
\hline Variable & Value \\
\hline$T_{g}$ & $80 \mathrm{~ms}$ \\
$T_{t}$ & $300 \mathrm{~ms}$ \\
$T_{r}$ & $10 \mathrm{~s}$ \\
$T_{p}$ & $20 \mathrm{~s}$ \\
$K_{r}$ & $1 / 2$ \\
$K_{p s}$ & 120 \\
$R$ & 2.4 Hertz/Megawatt \\
$B$ & 0.425 Megawatt/Hertz \\
$T_{12}$ & $86 \mathrm{~ms}$ \\
$T_{13}$ & $86 \mathrm{~ms}$ \\
$T_{23}$ & $86 \mathrm{~ms}$ \\
\hline
\end{tabular}

\section{HPSOGWO algorithm}

The HPSOGWO is a new hybrid optimization algorithm that combines PSO with GWO. The main goal of this hybridization is to improve the exploitation phase performance in PSO and enhance the capability of exploration of GWO [30].

\subsection{PSO technique}

The PSO algorithm is influenced by the way of living of animal groups like birds gathering and fish groups. During food searching, the birds are either distributed or fly in groups before reaching the destination. Usually, there's a bird in the group which has the instinct of smelling the food from a far distance. This bird transmits the food position to the group, finally purging on the food location [30]. Therefore, this animal conduct is employed in calculating the global optimization objective functions. Each member in the group is known as a particle. The following mathematical relations formulate the location of a single group member:

$$
\begin{gathered}
S_{i}^{t+1}=S_{i}^{t}+k_{1} n_{1}\left(P_{i}^{t}-Z_{i}^{t}\right)+k_{2} n_{2}\left(G^{t}-Z_{i}^{t}\right) \\
Z_{i}^{t=1}=Z_{i}^{t}+S_{i}^{t+1}
\end{gathered}
$$

where $t$ represents the iteration number, $k_{1}$ and $k_{2}$ represent the weighting factors, $n_{1}$ and $n_{2}$ are arbitrary numbers in the range of $[0,1], S_{i}^{t}$ represents particle velocity of particle $i$, $S_{i}^{t+1}$ represents the updated velocity of particle $i, Z_{i}^{t}$ is particle i position, $Z_{i}^{t+1}$ indicates the updated position of particle $i, P_{i}^{t}$ is the personal best particle $i$, while $G^{t}$ is the global best particle.

\subsection{Grey wolf optimization}

The Grey wolf optimization is inspired by the hunting manner and group ranking of grey wolves. The wolves have four ranks named alpha, beta, delta and omega. Grey wolves live in a group. The first rank in the group is alpha $(\alpha)$ which is the leadership rank. The alphas are one male and one female, and their tasks are to make decisions concerning the group. The second rank is beta $(\beta)$. The beta wolves help the alphas in their decisions. The third rank in the grey wolf hierarchy is omega $(\omega)$. The fourth type is delta $(\delta)$ wolves which obey the orders of alpha and beta, but they have a higher ranking than the omega wolves. The hunting conduct of the grey wolves can be divided into three main steps, exploration phase, surrounding the prey, and invading the prey [30]. The phase of surrounding the prey is formulated mathematically for each member in the group as follows:

$$
\begin{gathered}
\vec{B}=\left|\vec{K} \cdot \overrightarrow{Z_{p}(t)}-\overrightarrow{Z(t)}\right| \\
\overrightarrow{Z(t+1)}=\left|\overrightarrow{Z_{p}(t)}-\vec{F} \cdot \vec{B}\right|
\end{gathered}
$$

where vectors $B$ and $F$ are mathematically formulated according to the following relations:

$$
\begin{aligned}
& \vec{F}=2 \vec{f} \cdot \overrightarrow{n_{1}}-\vec{f} \\
& \vec{K}=2 \overrightarrow{n_{2}}
\end{aligned}
$$

Where $n_{1}$ and $n_{2}$ are arbitrary numbers within the range $[0,1]$ and $\vec{f}$ is considered to be factor decreased from 2 till reaching 0 throughout the iterative process. After the process of surrounding the prey, then the hunting phase starts. The hunting process can be expressed mathematically as follows: 


$$
\begin{aligned}
& \overrightarrow{b_{\alpha}}=\left|\overrightarrow{K_{1}} \cdot \overrightarrow{Z_{\alpha}}-\vec{Z}\right| \\
& \overrightarrow{b_{\beta}}=\left|\overrightarrow{K_{2}} \cdot \overrightarrow{Z_{\beta}}-\vec{Z}\right| \\
& \overrightarrow{b_{\delta}}=\left|\overrightarrow{K_{3}} \cdot \overrightarrow{Z_{\delta}}-\vec{Z}\right| \\
& \overrightarrow{Z_{1}}=\overrightarrow{Z_{\alpha}}-\overrightarrow{F_{1}} \cdot \overrightarrow{b_{\alpha}} \\
& \overrightarrow{Z_{2}}=\overrightarrow{Z_{\beta}}-\overrightarrow{F_{2}} \cdot \overrightarrow{b_{\beta}} \\
& \overrightarrow{Z_{3}}=\overrightarrow{Z_{\delta}}-\overrightarrow{F_{3}} \cdot \overrightarrow{b_{\delta}} \\
& \overrightarrow{Z_{2}}(t+1)=\frac{\overrightarrow{Z_{1}}+\overrightarrow{Z_{2}}+\overrightarrow{Z_{3}}}{3}
\end{aligned}
$$

\subsection{Hybrid PSO-GWO optimization}

The HPSOGWO algorithm is a combination between PSO and GWO. This hybrid algorithm is considered coevolutionary because both variants are operated in parallel, not one after the other. This hybridization enhances the capability of exploitation in the PSO technique and improves the capability of exploration in the GWO technique [30]. The best three agents are determined using the modified equation set as follows:

$$
\begin{aligned}
& \overrightarrow{b_{\alpha}}=\left|\overrightarrow{K_{1}} \cdot \overrightarrow{Z_{\alpha}}-w \vec{Z}\right| \\
& \overrightarrow{b_{\beta}}=\left|\overrightarrow{K_{2}} \cdot \overrightarrow{Z_{\beta}}-w \vec{Z}\right| \\
& \overrightarrow{b_{\delta}}=\left|\overrightarrow{K_{3}} \cdot \overrightarrow{Z_{\delta}}-w \vec{Z}\right|
\end{aligned}
$$

The variants of both algorithms are merged; hence the velocity is updated according to the following relations:

$$
\begin{aligned}
& S_{i}^{t+1}= w\left(S_{i}^{t}+k_{1} n_{1}\left(Z_{1}-Z_{i}^{t}\right)+k_{2} n_{2}\left(Z_{2}-Z_{i}^{t}\right)\right. \\
&\left.+k_{3} n_{3}\left(Z_{3}-Z_{i}^{t}\right)\right) \\
& S_{i}^{t+1}=Z_{i}^{t}+S_{i}^{t+1}
\end{aligned}
$$

\section{Simulation outcomes and discussion}

The system under study is a power system consisting of three areas, as depicted in Fig. 1 is constructed in MATLAB/SIMULINK environment, where the code of the HPSOGWO technique is loaded with the simulated system paradigm adjusting the controller gains. The values of the parameters used in the HPSOGWO technique are chosen to fulfil the requirements of robustness and convergence as in [14]. The population size $=30$ members, and the maximum bound of iterations $=500$. The PID controller coefficients are set to the range between 0 and 2 to compare with other techniques. The filter constant $(N)$ is set to the range between 0 and $100[3]$.
4.1 Scenario 1: Applying a step loading of $1 \%$ at the control area 1:

In this scenario, a step loading of $1 \%$ is applied to control area $1(\mathrm{SLP}=0.01)$. The results obtained by the HPSOGWO technique are compared with those obtained by the HS technique applied in [15] and the BFOA technique applied in

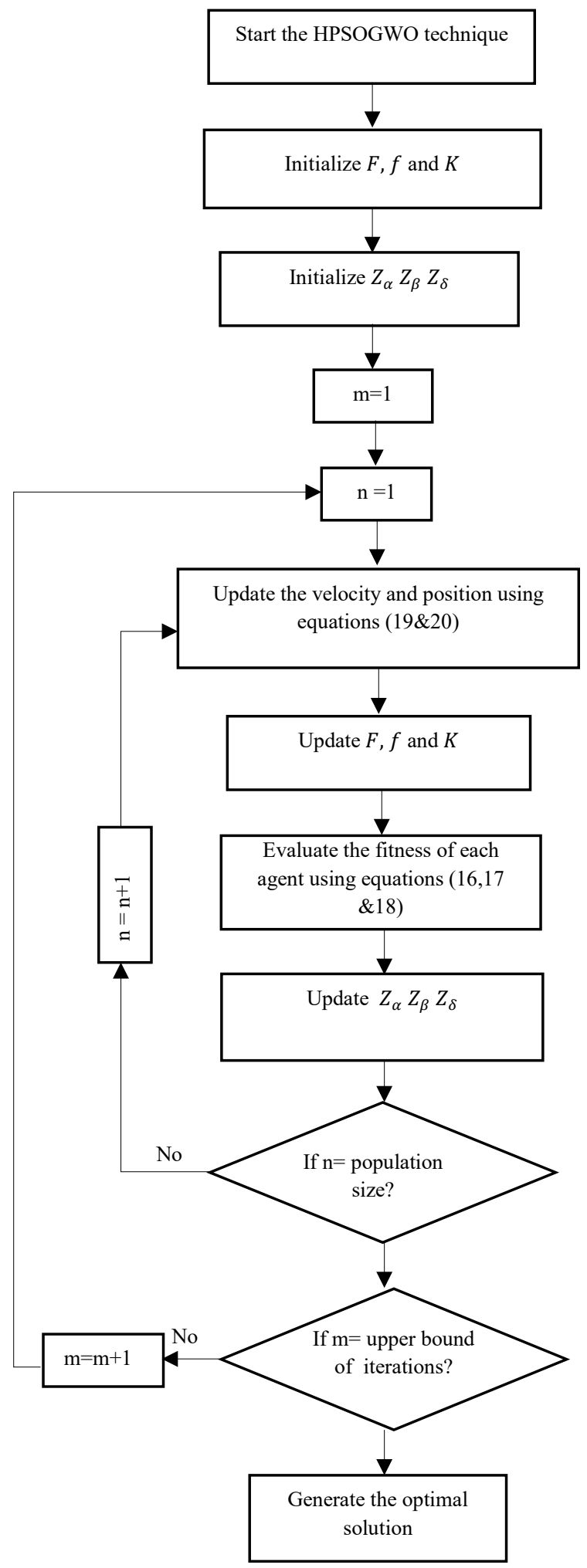

Fig.2. Flow diagram of the HPSOGWO technique 
[13].

Table 3 indicates the optimal values of the controller coefficients for all algorithms under comparison. The frequency variations in the three areas $\left(\Delta \mathrm{F}_{1}, \Delta \mathrm{F}_{2}\right.$ and $\left.\Delta \mathrm{F}_{3}\right)$ are demonstrated in Figs. 3-5, respectively. Figs. 6-8 describe the oscillations in the tie-line power in the three areas $\left(\Delta \mathrm{P}_{\text {tie }} 12\right.$, $\Delta \mathrm{P}_{\text {tie } 13}$ and $\Delta \mathrm{P}_{\text {tie } 23}$ ) respectively.

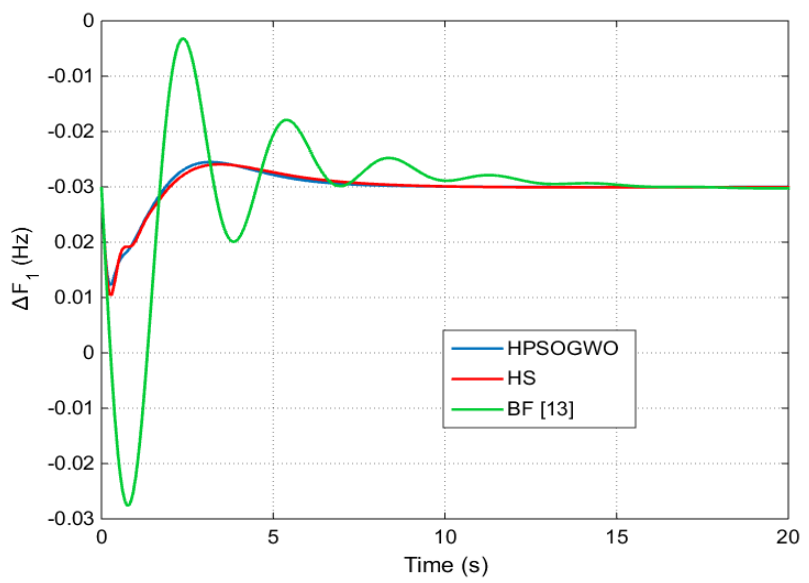

Fig.3. Time-domain frequency variations $\left(\Delta F_{1}\right)$ for the first scenario

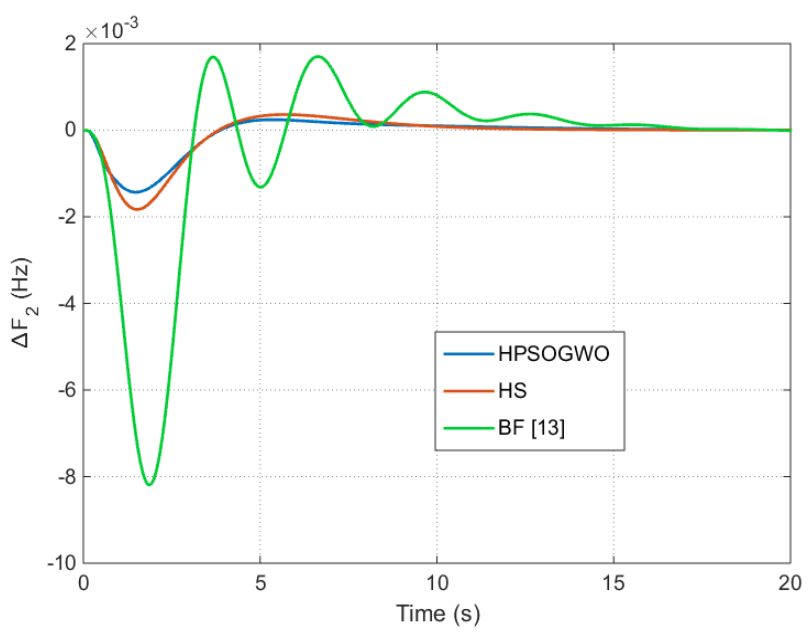

Fig.4. Time-domain frequency variations $\left(\Delta F_{2}\right)$ for the first scenario

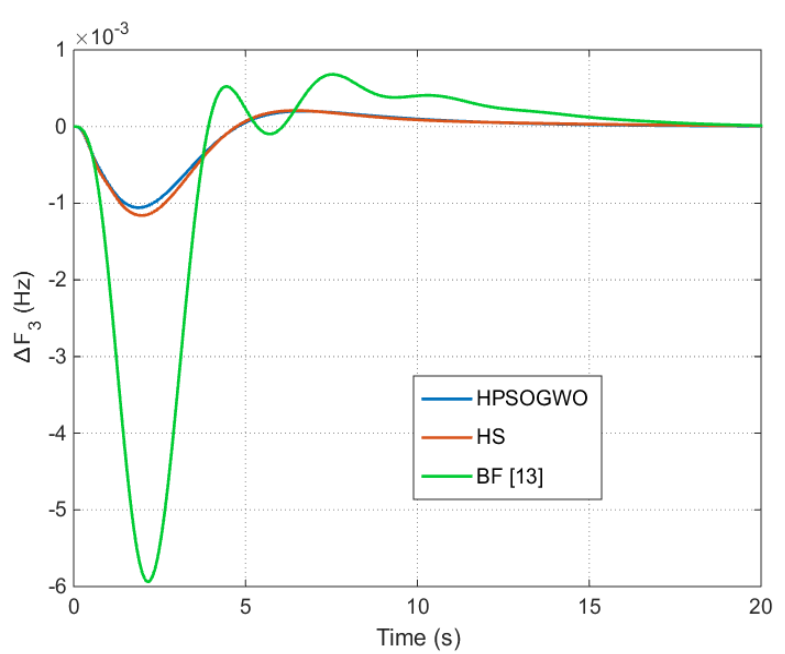

Fig.5. Time-domain frequency variations $\left(\Delta F_{3}\right)$ for the first scenario

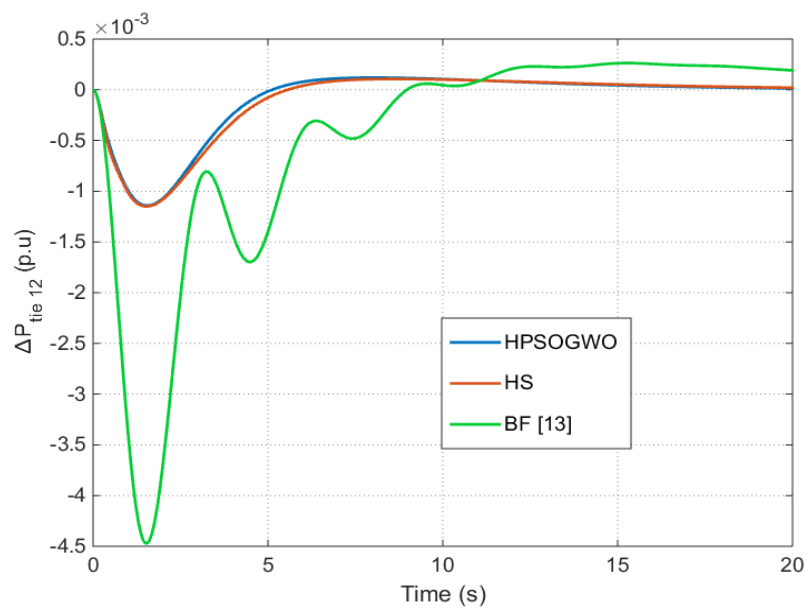

Fig.6. Time-domain tie line power variations $\left(\Delta P_{\text {tie } 12}\right)$ for the first scenario

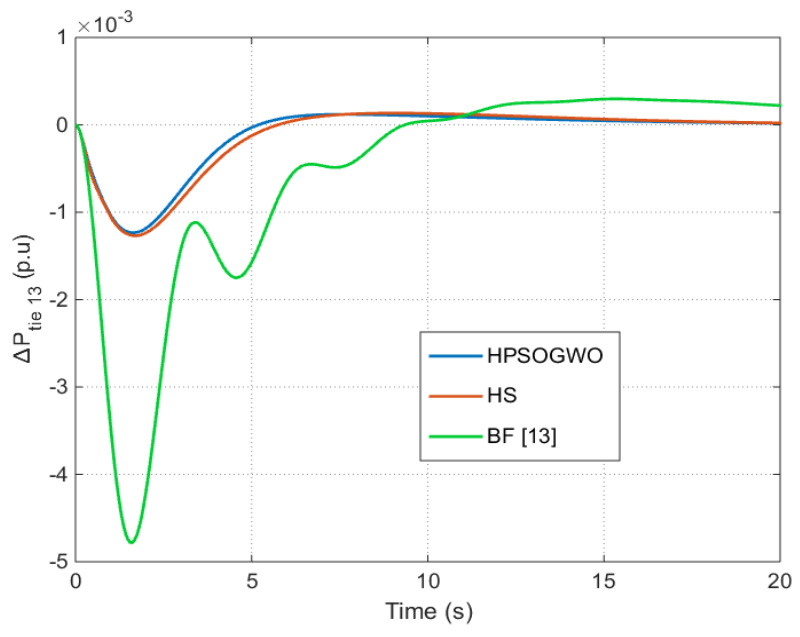

Fig.7. Time-domain tie line power variations $\left(\Delta P_{\text {tie } 13}\right)$ for the first scenario

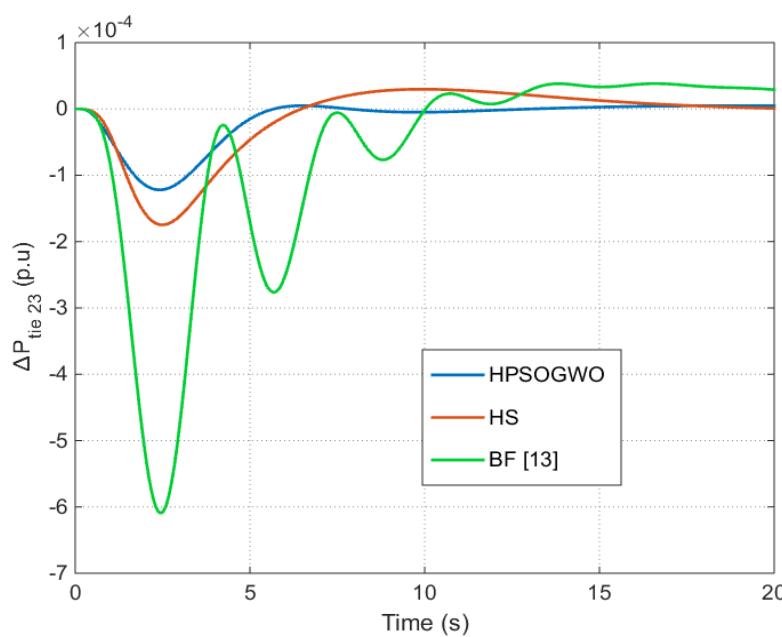

Fig.8. Time-domain tie line power variations $\left(\Delta P_{\text {tie } 23}\right)$ for the first scenario 


\begin{tabular}{lllll}
\hline & & HPSOGWO & HS & BFOA \\
\hline \multirow{4}{*}{ Controller 1 } & $K_{p 1}$ & 1.99 & 1.47 & -- \\
\cline { 2 - 5 } & $k_{i 1}$ & 1.98 & 1.79 & 0.4465 \\
\cline { 2 - 5 } & $k_{d 1}$ & 1.99 & 1.99 & -- \\
\cline { 2 - 5 } & $N_{1}$ & 34 & 16.78 & -- \\
\hline \multirow{4}{*}{ Controller 2 } & $k_{p 2}$ & 1.92 & 0.68 & -- \\
\cline { 2 - 5 } & $k_{i 2}$ & 1.71 & 0.27 & \\
\cline { 2 - 5 } & $k_{d 2}$ & 1.75 & 0.27 & -- \\
\cline { 2 - 5 } & $N_{2}$ & 39 & 21.78 & -- \\
\hline \multirow{3}{*}{ Controller 3 } & $k_{p 3}$ & 1.94 & 1.5 & -- \\
\cline { 2 - 5 } & $k_{i 3}$ & 0.38 & 1.3 & 0.2799 \\
\cline { 2 - 5 } & $k_{d 3}$ & 1.65 & 1.35 & -- \\
\cline { 2 - 5 } & $N_{3}$ & 51 & 13.7 & -- \\
\hline
\end{tabular}

Table 3 Optimal gain values of PID controllers

The transient performance parameters considered in this study are the maximum response, the minimum value of the response and the response settling time (using $2 \%$ criterion ). The simulation outcomes ensure the validity and supremacy of the suggested HPSOGWO technique over the rival algorithms under comparison.

\subsection{Scenario 2: Performance under various loading values in control region 1 :}

In the second scenario of this study, the network is tested under various loading conditions To approve the strength of the HPSOGWO algorithm. The gain values of the controllers are the same as the values acquired in scenario 1, which indicate the robustness of the suggested technique. The various loading conditions applied to the system are SLPs of $1 \%, 5 \%$ and $10 \%$ in area 1 at a time $(\mathrm{t})=$ zero. The response of frequency variations in the three areas is described in Figs. 9-11 while Figs. 12-14 show the time-domain tie-line power oscillations. The simulation outcomes are satisfying and within acceptable bounds.

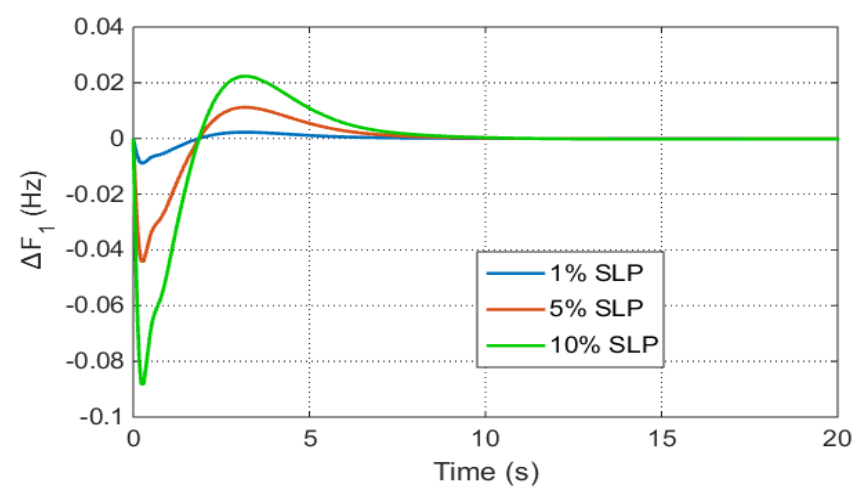

Fig.9. Time domain frequency variations $\left(\Delta F_{1}\right)$ for various loading percentages in area 1

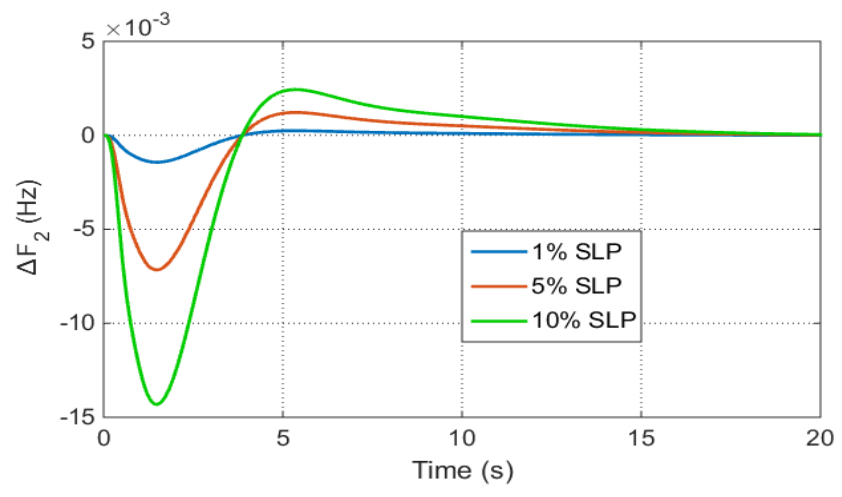

Fig.10. Time domain frequency variations $\left(\Delta \mathrm{F}_{2}\right)$ for various loading percentages in area 1

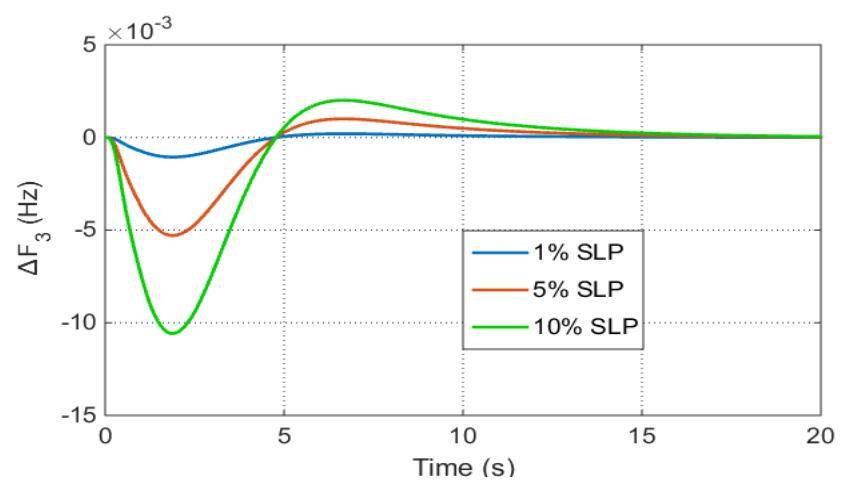

Fig.11. Time domain frequency variations $\left(\Delta \mathrm{F}_{3}\right)$ for various loading percentages in area 1

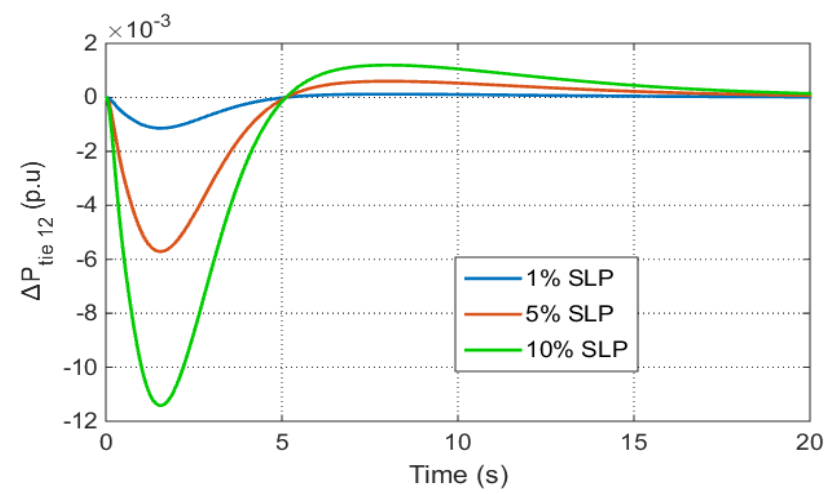

Fig.12. Time domain frequency variations $\left(\Delta P_{\text {tie }} 12\right)$ for various loading percentages in area 1

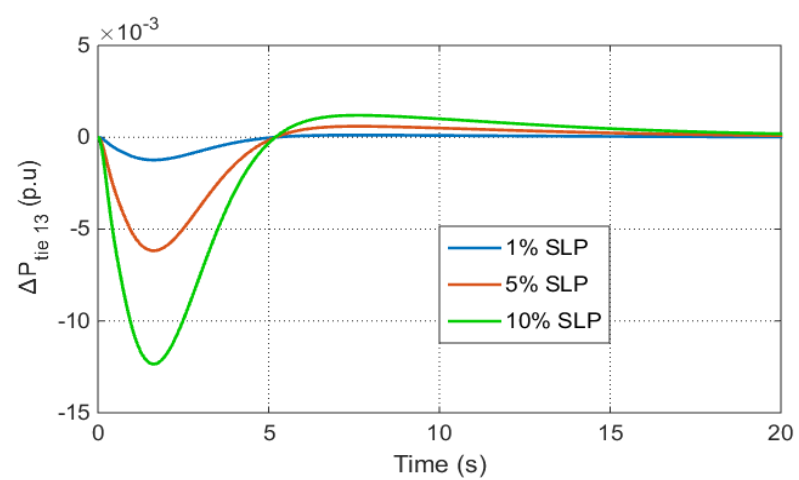

Fig.13. Time domain frequency variations $\left(\Delta \mathrm{P}_{\text {tie }} 13\right)$ for various loading percentages in region 1 
4.3 Scenario 3: Performance under changing the parameters of the system :

For the third scenario, the system is tested after changing the system parameters individually within a limit of $\pm 50 \%$. This test is performed to ensure the robustness of the suggested technique. The results acquired after changing the system parameters are close to the results obtained with nominal parameters. Also the gain values used in the first scenario are kept unchanged which ensure the stability of the suggested technique. The transient specifications of the obtained results are within acceptable limits. Table 4 shows the undershoots, overshoots and settling time of the frequency variations, while the transient specifications of tieline power variations are described in Table 5 .

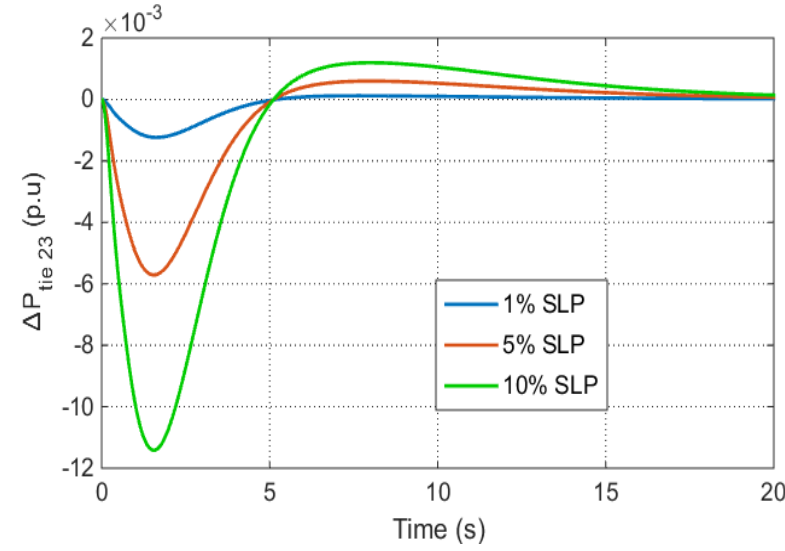

Fig.14. Time domain frequency variations $\left(\Delta P_{\text {tie } 23}\right)$ for various loading percentages in area 1

Table 4 Transient specifications of frequency variations at different system parameters

\begin{tabular}{|c|c|c|c|c|c|c|c|c|c|c|}
\hline \multirow{2}{*}{$\begin{array}{l}\text { System } \\
\text { parameter }\end{array}$} & \multirow[b]{2}{*}{ Change } & \multicolumn{3}{|l|}{ Delta f1 } & \multicolumn{3}{|l|}{ Delta f2 } & \multicolumn{3}{|l|}{ Delta f3 } \\
\hline & & $\begin{array}{l}\text { MPUS } \\
\text { (Hertz) }\end{array}$ & $\begin{array}{l}\text { MPOS } \\
\text { ( Hertz ) }\end{array}$ & $\begin{array}{l}T_{s} \\
\text { (seconds) }\end{array}$ & $\begin{array}{l}\text { MPUS } \\
\text { ( Hertz ) }\end{array}$ & $\begin{array}{l}\text { MPOS } \\
\text { ( Hertz ) }\end{array}$ & $\begin{array}{l}T_{S} \\
\text { (seconds) }\end{array}$ & $\begin{array}{l}\text { MPUS } \\
\text { ( Hertz ) }\end{array}$ & $\begin{array}{l}\text { MPOS } \\
\text { ( Hertz ) }\end{array}$ & $\begin{array}{l}T_{s} \\
\text { (seconds) }\end{array}$ \\
\hline Nominal & & $8.7 \times 10^{-3}$ & $2.24 \times 10^{-3}$ & 7.8 & $1.43 \times 10^{-3}$ & $2.4 \times 10^{-4}$ & 14.8 & $1.06 \times 10^{-3}$ & $2 \times 10^{-4}$ & 14.79 \\
\hline \multirow{2}{*}{$\mathbf{T}_{\mathrm{g}}$} & $+50 \%$ & $9.88 \times 10^{-3}$ & $2.23 \times 10^{-3}$ & 7.57 & $1.45 \times 10^{-3}$ & $2.38 \times 10^{-4}$ & 14.73 & $1.08 \times 10^{-3}$ & $2 \times 10^{-4}$ & 14.71 \\
\hline & $-50 \%$ & $7.5 \times 10^{-3}$ & $2.26 \times 10^{-3}$ & 8.13 & $1.41 \times 10^{-3}$ & $2.43 \times 10^{-4}$ & 14.87 & $1.05 \times 10^{-3}$ & $2.01 \times 10^{-4}$ & 14.88 \\
\hline \multirow{2}{*}{$\mathbf{T}_{\mathrm{t}}$} & $+50 \%$ & $10.65 \times 10^{-3}$ & $2.3 \times 10^{-3}$ & 7.41 & $1.62 \times 10^{-3}$ & $2.4 \times 10^{-4}$ & 14.31 & $1.16 \times 10^{-3}$ & $2.05 \times 10^{-4}$ & 14.32 \\
\hline & $-50 \%$ & $6.43 \times 10^{-3}$ & $2.24 \times 10^{-3}$ & 8.6 & $1.34 \times 10^{-3}$ & $2.46 \times 10^{-4}$ & 15.13 & $1 \times 10^{-3}$ & $2 \times 10^{-4}$ & 15.16 \\
\hline \multirow{2}{*}{$\mathbf{T}_{\mathrm{h}}$} & $+50 \%$ & $11.2 \times 10^{-3}$ & $3.05 \times 10^{-3}$ & 9.84 & $2.26 \times 10^{-3}$ & $4.5 \times 10^{-4}$ & 15.69 & $1.72 \times 10^{-3}$ & $4.72 \times 10^{-4}$ & 15.32 \\
\hline & $-50 \%$ & $6.03 \times 10^{-3}$ & $1.16 \times 10^{-3}$ & 6.63 & $7 \times 10^{-4}$ & $5 \times 10^{-5}$ & 8.65 & $5.05 \times 10^{-3}$ & $3.76 \times 10^{-6}$ & 6.64 \\
\hline \multirow{2}{*}{$\mathbf{K}_{\mathbf{h}}$} & $+50 \%$ & $1.53 \times 10^{-3}$ & $6.98 \times 10^{-3}$ & 6.89 & $9.4 \times 10^{-4}$ & $1.02 \times 10^{-4}$ & 12.56 & $6.9 \times 10^{-4}$ & $5.5 \times 10^{-5}$ & 13.14 \\
\hline & $-50 \%$ & $4.22 \times 10^{-3}$ & $13.3 \times 10^{-3}$ & 8.27 & $2.9 \times 10^{-3}$ & $8.58 \times 10^{-4}$ & 12.18 & $2.18 \times 10^{-3}$ & $8.65 \times 10^{-4}$ & 10.86 \\
\hline \multirow[b]{2}{*}{ B } & $+50 \%$ & $7.08 \times 10^{-3}$ & $1.97 \times 10^{-3}$ & 8.2 & $9 \times 10^{-4}$ & $1.59 \times 10^{-4}$ & 15.62 & $6.5 \times 10^{-4}$ & $1.18 \times 10^{-4}$ & 15.28 \\
\hline & $-50 \%$ & $12.4 \times 10^{-3}$ & $2.18 \times 10^{-3}$ & 7.6 & $2.08 \times 10^{-3}$ & $3.77 \times 10^{-4}$ & 13.79 & $2.12 \times 10^{-3}$ & $3.36 \times 10^{-4}$ & 14.02 \\
\hline \multirow{2}{*}{$\mathbf{R}$} & $+50 \%$ & $8.86 \times 10^{-3}$ & $2.46 \times 10^{-3}$ & 7.8 & $1.57 \times 10^{-3}$ & $3.03 \times 10^{-4}$ & 14.68 & $1.19 \times 10^{-3}$ & $2.73 \times 10^{-4}$ & 14.42 \\
\hline & $-50 \%$ & $8.51 \times 10^{-3}$ & $1.77 \times 10^{-3}$ & 8.22 & $1.1 \times 10^{-3}$ & $1.66 \times 10^{-4}$ & 15.04 & $7.71 \times 10^{-4}$ & $9.78 \times 10^{-5}$ & 15.54 \\
\hline
\end{tabular}

Table 5 Transient specifications of tie-line power variations at different system parameters

\begin{tabular}{|c|c|c|c|c|c|c|c|c|c|c|}
\hline \multirow{2}{*}{$\begin{array}{l}\text { System } \\
\text { parameter }\end{array}$} & \multirow[b]{2}{*}{ Change } & \multicolumn{3}{|c|}{ Delta Ptie 13} & \multicolumn{3}{|c|}{ Delta Ptie 12} & \multicolumn{3}{|c|}{ Delta Ptie 23} \\
\hline & & $\begin{array}{l}\text { MPUS } \\
\text { (p.u) }\end{array}$ & $\begin{array}{l}\text { MPOS } \\
\text { (p.u) }\end{array}$ & $\begin{array}{l}\mathbf{T}_{\mathbf{s}} \\
(\mathbf{s})\end{array}$ & $\begin{array}{l}\text { MPUS } \\
\text { (p.u) }\end{array}$ & $\begin{array}{l}\text { MPOS } \\
\text { (p.u) }\end{array}$ & $\begin{array}{l}\mathbf{T}_{\mathbf{S}} \\
(\mathbf{s})\end{array}$ & $\begin{array}{l}\text { MPUS } \\
\text { (p.u) }\end{array}$ & $\begin{array}{l}\text { MPOS } \\
\text { (p.u) }\end{array}$ & $\begin{array}{l}\mathbf{T}_{\mathrm{s}} \\
\text { (s) }\end{array}$ \\
\hline Nominal & & $1.237 \times 10^{-3}$ & $1.19 \times 10^{-4}$ & 15.38 & $1.14 \times 10^{-3}$ & $1.196 \times 10^{-4}$ & 15.81 & $1.21 \times 10^{-4}$ & $4.52 \times 10^{-6}$ & 14.64 \\
\hline \multirow[b]{2}{*}{$\mathbf{T}_{\mathrm{g}}$} & $+50 \%$ & $1.24 \times 10^{-3}$ & $1.21 \times 10^{-4}$ & 15.36 & $1.147 \times 10^{-3}$ & $1.22 \times 10^{-4}$ & 15.78 & $1.209 \times 10^{-4}$ & $3.45 \times 10^{-6}$ & 14.65 \\
\hline & $-50 \%$ & $1.236 \times 10^{-3}$ & $1.18 \times 10^{-4}$ & 15.4 & $1.144 \times 10^{-3}$ & $1.173 \times 10^{-4}$ & 15.83 & $1.218 \times 10^{-4}$ & $5.64 \times 10^{-6}$ & 14.71 \\
\hline \multirow{2}{*}{$\mathbf{T}_{\mathrm{t}}$} & $+50 \%$ & $1.29 \times 10^{-3}$ & $1.26 \times 10^{-4}$ & 15.19 & $1.2 \times 10^{-3}$ & $1.29 \times 10^{-4}$ & 15.59 & $1.25 \times 10^{-4}$ & $1.2 \times 10^{-6}$ & 14.26 \\
\hline & $-50 \%$ & $1.21 \times 10^{-3}$ & $1.15 \times 10^{-4}$ & 15.49 & $1.117 \times 10^{-3}$ & $1.1 \times 10^{-4}$ & 15.95 & $1.204 \times 10^{-4}$ & $8.4 \times 10^{-6}$ & 14.94 \\
\hline \multirow{2}{*}{$\mathbf{T}_{\mathrm{h}}$} & $+50 \%$ & $1.704 \times 10^{-3}$ & $1.96 \times 10^{-4}$ & 16.82 & $1.57 \times 10^{-3}$ & $2.1 \times 10^{-4}$ & 17.32 & $1.77 \times 10^{-4}$ & $2.99 \times 10^{-5}$ & 17.34 \\
\hline & $-50 \%$ & $7.3 \times 10^{-4}$ & $1.23 \times 10^{-5}$ & 6.1 & $6.76 \times 10^{-4}$ & $1.86 \times 10^{-5}$ & 8.17 & $7.14 \times 10^{-5}$ & $1.1 \times 10^{-8}$ & 8.8 \\
\hline \multirow{2}{*}{$\mathbf{K}_{\mathbf{h}}$} & $+50 \%$ & $9.15 \times 10^{-4}$ & $4.73 \times 10^{-5}$ & 11.31 & $8.47 \times 10^{-4}$ & $4.96 \times 10^{-5}$ & 12.26 & $8.88 \times 10^{-5}$ & $6.11 \times 10^{-5}$ & 11.67 \\
\hline & $-50 \%$ & $1.97 \times 10^{-3}$ & $2.88 \times 10^{-4}$ & 16.04 & $1.83 \times 10^{-3}$ & $3.08 \times 10^{-4}$ & 16.27 & $2.12 \times 10^{-4}$ & $1.53 \times 10^{-6}$ & 15.21 \\
\hline \multirow{2}{*}{ B } & $+50 \%$ & $1.06 \times 10^{-3}$ & $7.52 \times 10^{-5}$ & 15.59 & $9.92 \times 10^{-4}$ & $8.73 \times 10^{-5}$ & 16.32 & $8.7 \times 10^{-5}$ & $2.94 \times 10^{-6}$ & 17.39 \\
\hline & $-50 \%$ & $1.512 \times 10^{-3}$ & $1.87 \times 10^{-4}$ & 14.91 & $1.378 \times 10^{-3}$ & $1.72 \times 10^{-4}$ & 14.8 & $1.878 \times 10^{-4}$ & $1.53 \times 10^{-5}$ & 14.78 \\
\hline $\mathbf{R}$ & $+50 \%$ & $1.281 \times 10^{-3}$ & $1.11 \times 10^{-4}$ & 14.95 & $1.183 \times 10^{-3}$ & $1.1 \times 10^{-4}$ & 15.68 & $1.275 \times 10^{-4}$ & $1.8 \times 10^{-5}$ & 16.01 \\
\hline
\end{tabular}




\section{Conclusion}

This article has presented the HPSOGWO approach, a recent hybrid optimization approach to design the PID controllers employed to control the frequency of an electrical network consisting of three areas. The controller gains produced by the HPSOGWO algorithm are put in comparison with those acquired by other algorithms. The results have shown that the transient specifications of time-domain deviations of frequency and tie-line power are better than those produced by the other techniques under comparison. The responses resulting from the HPSOGWO technique are faster and less damped. The study examines the effect of varying the loading percentages to prove the robustness of the suggested technique.

Moreover, the study examines the consequences of varying the system parameters to simulate the operation of real power networks. The HPSOGWO algorithm produces good results after varying the system parameters. Consequently, the HPSOGWO technique has shown to be highly efficient and resilient in tackling the load frequency control problem.

\section{References}

[1] X. Chen, C. Zhao and N. Li, "Distributed Automatic Load Frequency Control With Optimality in Power Systems," in IEEE Transactions on Control of Network Systems, vol. 8, no. 1, pp. 307-318, March 2021, doi: 10.1109/TCNS.2020.3024489.

[2] K. S. Xiahou, Y. Liu and Q. H. Wu, "Robust Load Frequency Control of Power Systems Against Random Time-Delay Attacks," in IEEE Transactions on Smart Grid, vol. 12, no. 1, pp. 909-911, Jan. 2021, doi: 10.1109/TSG.2020.3018635.

[3] Hasanien, H.M., El-Fergany, A.A., "Symbiotic organisms search algorithm for automatic generation control of interconnected power systems including wind farms," IET Gener. Transm. Distrib., 2017, 11, (7), pp. 1692-1700.

[4] Kumar, A., Shankar, G.: "Load frequency control assessment of tidal power plant and capacitive energy storage systems supported microgrid" IET Generation, Transmission \& Distribution, 2020, 14, (7), pp. 1279-1291

[5] Sobhy, M.A., Abdelaziz, A.Y., Hasanien, H.M., Ezzat, M.: "Marine predators algorithm for load frequency control of modern interconnected power systems including renewable energy sources and energy storage units" Ain Shams Engineering Journal, 2021.

[6] Golkhandan, R.K., Torkaman, H., Aghaebrahimi, M.R., Keyhani, A.: "Load frequency control of smart isolated power grids with high wind farm penetrations" IET Renewable Power Generation, 2020, 14, (7), pp. 1228-1238.

[7] Farag K. Abo-Elyousr, Ali M. Youssef and A. Y. Abdelaziz, "Multi Area Hydrothermal Interconnected Load Frequency Control with Double Fed Induction Generator Based Wind Turbine via Improved Harmony Algorithm," Electric Power Components and Systems Journal, Vol. 46, Issue 6, 2018, pp. 615-628.

[8] A. Y. Abdelaziz and Ehab S. Ali, "Cuckoo Search Algorithm Based Load Frequency Controller Design for Nonlinear Interconnected Power System," International Journal of Electrical Power and Energy Systems, Vol. 73, December 2015, pp. 632-643.

[9] Yousel, H.A., Kharusi, K.A.L., Albadi, M.H., et al.: 'Load frequency control of a multi-area power system: an adaptive fuzzy logic approach', IEEE Trans. Power Syst., 2014, 29, (4), pp. 1822-1830

[10] Hasanien, H.M., Muyeen, S.M.: 'A Taguchi approach for optimum design of proportional-integral controllers in cascaded control scheme', IEEE Trans. Power Syst., 2013, 28, (2), pp. 1636-1644
[11] Hasanien, H.M., Muyeen, S.M.: 'Affine projection algorithm based adaptive control scheme for operation of variable speed wind generator', IET Gener. Transm. Distrib., 2015, 9, (16), pp. 2611-2616

[12] Hasanien, H.M.: 'Gravitational search algorithm-based optimal control of Archimedes wave swing-based wave energy conversion system supplying a DC microgrid under uncertain dynamics', IET Renew. Power Gener., 2017, 11, (6), pp. 763-770

[13] Ali, E.S., Abd-Elazim, S.M., "BFOA based design PID controller for two-area load frequency control with nonlinearities," Int. J. Electr. Power Energy Syst., 2013, 51, pp. 224-231, doi: 10.1016/j.ijepes.2013.02.030.

[14] M. Shivaie, M. G. Kazemi, and M. Ameli, "A modified harmony search algorithm for solving load frequency control of nonlinear interconnected hydrothermal power systems," Sustain. Energy Technol. Assessments, vol. 10, pp. 53-62, June 2015. doi:10.1016/j.seta.2015.02.001

[15] Shiva, C.K., Shankar, G., Mukherjee, V.: 'Automatic generation control of power system using a novel quasi-oppositional harmony search algorithm', Int. J. Electr. Power Energy Syst., 2015, 73, pp. 787-804, doi: $10.1016 /$ j.jestch.2015.07.013

[16] El-Fergany, A.A., Elhameed, M.A.: 'Efficient frequency controllers for autonomous two-area hybrid microgrid system using social-spider optimizer', IET Gener. Transm. Distrib., 2016, In press, doi: 10.1049/iet-gtd.2016.0455

[17] M. Omar, M. Ebrahim, A. Abdel-ghany, and F. Bendary, "Harmony searched based PID for multi area load frequency including boiler dynamics and nonlinearities," WEAS Trans. Circuits Syst., vol. 14, pp. 406-413, January 2015.

[18] Alomoush, M.I.: 'Load frequency control and automatic generation control using fractional order controllers', Electr. Eng., 2010, 91, pp 357-368

[19] Zeynelgil, H.L., Demiroren, A., Sengor, N.S.: 'Load frequency controls for power system with reheat steam turbine and governor dead band non-linearity by using neural network controller', Eur. Trans. Electr. Power, 2002, 12, (3), pp. 179-184

[20] Othman,Ahmed M. et al., "Design of robust model predictive controllers for frequency and voltage loops of interconnected power systems including wind farm and energy storage system," IET Generation, Transmission \& Distribution(2018), 12 (19):4276

[21] Patra, S., Sen, S., Ray, G.: 'Design of robust load frequency controller: $\mathrm{H} \infty$ loop shaping approach', Electr. Power Compon. Syst., 2007, 35 , (7), pp. 769-783

[22] Khuntia, S.R., Panda, S.: 'Simulation study for automatic generation control of a multi-area power system by ANFIS approach', Appl. Soft Comput., 2012,12, pp. 333-341

[23] Vrdoljak, K., Perié, N., Petrovié, I.: 'Sliding mode based loadfrequency control in power systems', Electr. Power Syst. Res., 2010 $80,(5)$, pp. $514-527$

[24] Juang, C.F., Lu, C.F.: 'Load frequency control by hybrid evolutionary fwhauzzy PI-controller', IEE Proc. Gener. Transm. Distrib., 2006, 153, (2), pp. 196-204

[25] Tan, W., Xu, Z.: 'Robust analysis and design of load frequency controller for power systems', Electr. Power Syst. Res., 2009, 79, (5), pp. 846-853, doi: 10.1016/j.epsr.2008.11.005

[26] Ramesh S, Krishnan A., "Modified genetic algorithm based load frequency controller for interconnected power system," Int J Electr Power Eng 2009;3(1): 26-30

[27] Padhan, S., Sahu, RK, Panda, S., "Application of firefly algorithm for load frequency control of multi area interconnected power system," Electr. Power Compon. Syst., 2014, 42, (13), pp. 1-12, doi: 10.1080/15325008.2014.933372.

[28] Hany M. Hasanien, "Whale optimization algorithm for automatic generation control of interconnected modern power systems including renewable energy sources," Generation Transmission \& Distribution IET, vol. 12, no. 3, pp. 607-614, 2018.

[29] Gozde, H., Taplamacioglu, M.C., Kocaarslan, I, "Comparative performance analysis of artificial bee colony algorithm in automatic generation control for interconnected reheat thermal power system," Int. J. Electr. Power Energy Syst., 2012, 42, (1), pp. 167-178, doi: 10.1016/j.ijepes.2012.03.039. 
[30] N.Singh, S.Singh, "Hybrid Algorithm of Particle Swarm Optimization and Grey Wolf Optimizer for Improving Convergence Performance," Journal of applied Mathematics Vol. 2017, Article ID 2030489.

[31] Hany M. Hasanien, Attia A. El-Fergany, "Salp swarm algorithm-based optimal load frequency control of hybrid renewable power systems with communication delay and excitation cross-coupling effect," Electric Power Systems Research, ,2019, ISSN: 0378-7796, Vol: 176.

[32] Fathy, A., Kassem, A.M., Abdelaziz, AY: "Optimal design of fuzzy PID controller for deregulated LFC of multi-area power system via mine blast algorithm" Neural Computing and Applications, 2018, 32, (9), pp. 4531-4551.

[33] Abo-Elyousr, F.K., Abdelaziz, AY: "A Novel Modified Robust Load Frequency Control for Mass-Less Inertia Photovoltaics Penetrations via Hybrid PSO-WOA Approach" Electric Power Components and Systems, 2019, 47, (19-20), pp. 1744-1758.

[34] Choudhary, A.K., Prakash, S., Sharma, M., Dhundhara, S.: "Grasshopper optimization based robust power/frequency regulator for shipboard micro - grid" IET Renewable Power Generation, 2020, 14, (17), pp. 3568-3577.

[35] Sharma, M., Dhundhara, S., Arya, Y., Prakash, S.: "Frequency stabilization in deregulated energy system using coordinated operation of fuzzy controller and redox flow battery" International Journal of Energy Research, 2020, 45, (5), pp. 7457-7475.

[36] Sharma, M., Prakash, S., Saxena, S., Dhundhara, S.: "Optimal Fractional-Order Tilted-Integral-Derivative Controller for Frequency Stabilization in Hybrid Power System Using Salp Swarm Algorithm" Electric Power Components and Systems, 2020, 48, (18), pp. 19121931.

[37] Sharma, M., Prakash, S., Saxena, S.: "Robust Load Frequency Control Using Fractional-order TID-PD Approach Via Salp Swarm Algorithm" IETE Journal of Research, 2021, pp. 1-17.

[38] Sharma, M., Dhundhara, S., Arya, Y., Prakash, S.: "Frequency excursion mitigation strategy using a novel COA optimized fuzzy controller in wind integrated power systems" IET Renewable Power Generation, 2020, 14, (19), pp. 4071-4085. 